\title{
Study on the Application of Case Teaching Method in the Cultivation of Master of Professional Clinical Surgery
}

\author{
Yijin Zheng, Jinjun $\mathrm{Li}^{*}$, Qingming Wu*, Yinxia Wu, Manqin Guo, Ting Yu \\ Medical College, Wuhan University of Science and Technology, Wuhan, China \\ Email: *Jinjun Li entry2003@126.com, *wuhe9224@sina.com
}

How to cite this paper: Zheng, Y. J., Li, J. J., Wu, Q. M., Wu, Y. X., Guo, M. Q., \& Yu, T. (2018). Study on the Application of Case Teaching Method in the Cultivation of Master of Professional Clinical Surgery. Creative Education, 9, 272-279.

https://doi.org/10.4236/ce.2018.92017

Received: July 19, 2017

Accepted: February 11, 2018

Published: February 14, 2018

Copyright $\odot 2018$ by authors and Scientific Research Publishing Inc.

This work is licensed under the Creative

Commons Attribution International

License (CC BY 4.0).

http://creativecommons.org/licenses/by/4.0/

\begin{abstract}
Clinical case teaching method, refers to the use of carefully selected cases, through the positive guidance of teachers and students' autonomic learning, to enable students to understand the system in clinical medicine theory knowledge, and master the basic clinical skills. In the case teaching of clinical medicine, the choice of the case and the design of the problem are the keys.
\end{abstract}

\section{Keywords}

Postgraduate Education, Reform in Education, Case Teaching Method

\section{Introduction}

Surgery is a professional and practical subject. In order to meet the training needs of high-quality medical talents, to achieve convergence with the modern occupation physician examination system, cultivating fine noble medical ethics, worthy of the technology, can make full use of the theoretical knowledge and practical ability in clinical surgery medical technical personnel. We take the master degree of clinical medicine in surgery as the research object, to explore the application effect of the teaching method of clinical cases in science and culture, research on medical students' analysis of surgical disease, basic skills, clinical thinking ability and doctor-patient communication skills. This new type of training mode is mainly to cultivate good clinical practice ability, and has a certain degree of clinical scientific research ability of high-level medical talents. And it ensures the quality of clinical medicine professional degree graduate training, and can effectively save education and training resources and improve the efficiency of personnel training, professional degree graduate education to 
solve the problem of qualification certification. Postgraduate education is the highest level of China's higher education. Constantly improving the quality of graduate education is the key to enhance the core competitiveness of our country (Li, Wu, Yu et al., 2016).

1) Case teaching method refers to education in theory and actual organic combination of purposes. According to the teaching objective, with clinical cases as the basic teaching material, medical students will introduce a real situation in the clinical. Through the equal interaction and discussion between teachers and students, students and students, we mainly focus on the training of students' clinical logic thinking, the ability to reason and judge, to achieve the teaching method of high level cognitive learning objectives (Reeves, Perrier, Goldman et al., 2013).

Case teaching is based on the students' basic medical knowledge and clinical analysis, under the teacher's careful planning and guidance and also conforms to the teaching objectives and teaching content requirements. Case teaching mainly uses typical cases as well as specific case analysis of student's website, through cultivating students' ability to think independently and cooperate collectively, to further improve the recognition analysis abilities and abilities to solve specific problems, and teach them correct management ideas, work styles, communication skills and teamwork spirits.

2) The characteristics of the case teaching method and the advantages in the application of the external science teaching

The case teaching method of case teaching has obvious advantages in the practical teaching of medical practice. The research and exploration of case teaching method is helpful to improve the teaching quality and cultivate the high-quality medical talents. One of the remarkable characteristics of case teaching method is to stimulate students' subjective initiative. Let the students feel their own cases, their observation, analysis, thinking, so that they understand the truth, their grasp of the law of development and change. It focuses on the theory of teaching, pays more attention to the practice teaching, clinical cases plot, makes the students consciously enter into the check of diseases, sets auxiliary examination and treatment work "in the field", using the learned knowledge and the enlightenment of classroom teaching as well as active collection of clinical data analysis, reasoning, judgment, possibility of clear diagnosis, to promote their thinking, decision-making. The process of passive listening to students is a process of active thinking and active participation, which can give full play to the initiative of each student and fully mobilize the enthusiasm of the students. What is the important standard to measure teaching methods? An excellent case is a tool for teachers and students to interact with a specific case, and is also a class discussion based on the fact that the clinical practice will definitely occur.

\subsection{To Improve the Comprehensive Quality of Clinical Postgraduates}

In the teaching of surgery, there is a large amount of information the pathogene- 
sis, clinical manifestations and treatment of each disease, the traditional teaching method of classroom teaching is often boring, boring classroom atmosphere, students cannot attract attention. The use of clinical case teaching method has the advantages of specificity, flexibility and interactivity, so it can help students to understand the information through a variety of clinical situations. The clinical case teaching method through the analysis of the actual case, students will learn the anatomy, pathophysiology, symptoms, diagnosis and other basic medical knowledge applied to clinical case, mastery, mutual penetration, flexible use. Not only to consolidate the knowledge, but also to improve the students' comprehensive ability and the ability to solve clinical diagnosis and other issues. Graduate students through the discussion of real cases, in the class at the same time as if personally on the scene, naturally into the role of doctors, At the same time feel the teacher's clinical thinking, we can feel the clinical thinking and experience the whole process of clinical analysis, thinking, reasoning and judgment, Fully appreciate the fun and help of active participation, discovery, teamwork and interesting learning methods to bring happiness and efficiency. It is helpful to cultivate students' ability to analyze and solve problems independently. The case teaching method provides a more personalized, multi-channel access to knowledge for each student, in close connection with the actual learning theory to improve the comprehensive quality of students, which laid the foundation for the lifelong development of students.

\subsection{Improve the Level of Clinical Teaching}

The clinical case teaching method, encourage teachers to clinical practice in an extensive collection of various complex cases, and to collect the data of scientific arrangement, different case selection applies to clinical teaching needs; at the same time according to the change and development of constant renewal of medical theory and medical technology, timely update and necessary thus, teachers' teaching and scientific research level has been constantly improving. Teachers can guide students to analyze process to solve practical problems in clinical cases, and continue to explore and improve clinical case teaching method, is a process of learning, the professional quality of teachers to be further improved.

\section{Selected Cases of Surgery}

\subsection{Selection of the Typical Clinical Cases of Surgery}

The choice of clinical cases is the basis and prerequisite for the implementation of case teaching method, and the content and quality of clinical cases have a direct impact on the teaching effect:

1) The choice of cases should be clear teaching objectives, highlighting the clinical theme. To enable students to deepen the understanding of the key and difficult points of diagnosis and treatment of clinical diseases in the course of discussion, and to use the lessons learned theoretical knowledge and clinical 
case, deepen understanding and mastery. For example, extensive anterior wall acute myocardial infarction cases with cholecystitis and gallstone differential diagnosis, misdiagnosis can lead to rapid death if the patient, it stressed the differential diagnosis of abdominal pain in the process of analysis and discussion in acute abdomen and abdominal disease identification highlights the importance of the students' clinical thinking ability is extended from the local to the whole, improve the students' analysis and the solution to a problem.

2) Clinical cases should be objective, vivid and typical clinical cases. Cases originated from the common and frequently occurring diseases in clinical practice. Has a certain degree of comprehensiveness, can reflect the content of the theory of the system, and is conducive to inspire students' thinking. Teachers should be the actual medical activities, perplexing the myriads of changes, be arranged to choose and sort out the clinical representative example, the students can play an important role, by analogy. At the same time, the case must be lively and vivid and attractive choice, so as to arouse the interest of students, in order to further discuss.

\subsection{Selected Typical Clinical Cases}

The difficulty degree of clinical cases should be moderate, and the amount of clinical information is appropriate. Teaching cases to be a certain degree of difficulty, not too simple. It is necessary to consciously choose some complex and critical cases that are easy to cause misdiagnosis, stimulate students' interest in learning, probe into the causes of the problem, access to information, and analyze deeply. In addition, for the key issues to be reflected in the case, teachers should provide clear information to facilitate the use of cases and case teaching. The case is enough to arouse interest in thinking and arguing, and it is instructive.

\section{Implementation of Surgical Clinical Case Teaching}

\subsection{Surgical Case Setting}

Clinical case design is the key to the successful implementation of case teaching. The design of the case can be basic medical knowledge, for example, the right upper abdomen which organs are included ; Clinical cases can also be comprehensive, reasoning about clinical expertise, such as the use of the collection of history, clinical manifestations, signs and auxiliary examination data to determine what is the most likely diagnosis? and so forth. Under normal circumstances, the case should be arranged according to the arrangement of the curriculum, the curriculum content is simple and complex, and gradually into the deeper. When choosing the real case, the final diagnosis and pathological results of the case are hidden, leaving enough space for students to participate in classroom discussions.

\subsection{Implementation Method of Case Teaching}

First of all, let the students have a full understanding of the case and analysis. 
Published clinical case content before the lecture 1 - 2 weeks before the commencement of clinical cases, students are required to find a similar case further around the collection of clinical data and literature information, can make students better to actively participate in the teaching process. A clinical case discussion group, set up a study group based on each other willing on the formation of "learning community" of general 4 - 6 is appropriate, provided to participate in the exchange seminars for each student, opportunities to express their views and ideas, cultivate the spirit of teamwork, enhance the learning effect of the case. Case-based education can direct students as they learn complex medical decision-making skills, including how to approach the undifferentiated patient, apply relevant medical knowledge, and create logical management plans. In 1 study, fourth-year medical students reported a need to learn how to formulate treatment plans (Bernard, Balodis, Kman et al., 2013).

Case analysis of the classroom should be used as far as possible to discuss the method of analysis, that is, students play the leading role, to encourage students to fully discuss, the teacher only as a guide, to guide the case discussion, timely guidance or induction summary. If the teacher before the discussion related to the basic medical knowledge (such as the concept or content system) to explain, it should not be too long. If the teacher does not introduce the basic knowledge of the medicine before the discussion, the students can be asked to integrate the basic medical knowledge in the discussion.

In the discussion of the students, teachers should pay special attention to the problems in the discussion of the students and the innovation of ideas, so as to adjust the key points of the classroom teaching in time, and make the case teaching more pertinent, in addition to comment on the student's discussion process.

In the course of summing up, In addition to comment on the student's discussion process (such as ideas, demonstration methods, problems, etc.) teacher should also be noted that according to the logic of teaching content of the process of analysis and conclusion complete, especially the performance of key clinical differential diagnosis in patients involved should also be extended to explain the value of and in order to improve the actual effect of case teaching.

Using cases derived from patients that students have actually cared for in the clinical setting combines experiential learning with an organized approach in a low stress environment, without adverse effects on patient safety. Small group case conferences, such as the one in our study, may also appeal to learner partialities as clerkship students have reported tutorials and preceptor-assisted learning sessions among their curricular preferences) (Yeung, Beecker, Marks et al., 2010). This setting also provides novice learners deliberate access to the thought process of a seasoned clinician expert. In a study by Ilgen et al., novices and experts approached clinical scenarios using different strategies (Ilgen, Bowen, McIntyre et al., 2013). 


\section{After-School Practice}

The students completed a written analysis report to the case discussion topic in 1500 - 3000 words. To help students master the content of this case discussion, to further consolidate the clinical knowledge, you can also exercise in the future clinical work skills.

\subsection{Some Problems Should Be Paid Attention to in the Case Teaching of Clinical Medicine}

Case teaching method requires students to master some theoretical knowledge, only students in the understanding of the theoretical knowledge of the premise, in order to fully carry out case analysis and discussion, to achieve the purpose of teaching. For diagnostics, internal medicine teaching in clinical medicine, review the etiology, mechanism of disease, symptoms, signs and laboratory examination of basic knowledge is essential, the advantages of the case teaching method can only complement each other with the classic clinical teaching method in perfect teaching effect.

\subsection{Full Preparation before Class}

The perfect pre class preparation is an important guarantee for the smooth implementation of case teaching. First of all, teachers must be proficient in the entire case data, familiar with the basic theory of medical theory to be involved in teaching; Secondly, the teacher can predict the possible clinical ideas and perspectives that students may present and determine the timing of their involvement in the discussion, to develop a careful case study to guide the program; Third, teachers collect information, such as symptoms, signs, auxiliary examination and so on. The use of text, graphics, images, sound and other multimedia teaching methods of teaching methods, so that it seems to pro clinical diagnosis and treatment scenarios, to better attract the attention of students, improve learning.

\subsection{Control the Each Links and Nodes of Case Teaching}

Case teaching emphasizes the control of teaching time, content and form. Case teaching is different from general clinical medical teaching, In the case of the process of teaching, teachers should not only in order to arrange the teaching schedule, but also requires teachers to have the ability to completely control the course of. In the analysis of the classroom, the teacher should listen carefully to the discussion and analysis of the case analysis, put forward the key questions in time, make the students to think more deeply about the problem, or adjust the direction of clinical thinking; Teachers should timely sum up the suggestions or opinions of the students, help the students to sort out the clinical ideas, and establish their views on the basis of solid medical theory. The professor to create a normal discussion learning atmosphere; according to discuss the clinical significance and the degree of difficulty to allocate time for discussion, using a variety 
of different ways to effectively control the process of classroom discussion, seeking to achieve the desired effect is discussed.

\section{Summary}

Case teaching method is the result of quality education reform. It plays an important role in the teaching of clinical medicine in Colleges and universities. It is necessary to combine the current situation of medical reform. We should adjust the training objectives and training programs of clinical medical personnel, and establish a systematic and abundant case teaching resource library. At the same time, teachers should make corresponding changes in the concept of education, teaching methods, teaching methods, etc. Only in this way can we cultivate the practical and innovative medical talents with solid basic skills and strong working ability. The case-based approach was a successful educational modality for practicing with difficult case scenarios before engaging in similar scenarios with colleagues during actual clinical care (Gooding, Ziniel, Touloumtzis et al., 2016). Our research supports previous literature that shows the importance of instructing EM clerkship students how to approach case of emergent patient (Ilgen, Bowen, McIntyre et al., 2013). Case conferences are resource-intensive in terms of creation of materials and faculty instructor time, but our study suggests that the benefits are worth the investment. Despite improved outcomes with a combined clinical requirement, self-study, and passive large group didactics, there is still potential for improved learning. Our study demonstrated a significant gain in learner knowledge and clinical reasoning when an expert guided them in a small group format to solve cases that they had experienced in lecture, reading, and the clinical arena. Benedek et al. are convinced that urging the students to make case studies can contribute to activate students' learning enthusiasm (Benedek \& Horváth Cz., 2016).

\section{References}

Benedek, A., \& Horváth Cz., J. (2016). Case Studies in Teaching Systems Thinking. IFAC-PapersOnLine, 49, 286-290. https://doi.org/10.1016/j.ifacol.2016.07.191

Bernard, A. W., Balodis, A., Kman, N. E., Caterino, J. M., \& Khandelwal, S. (2013). Medical Student Self-Assessment Narratives: Perceived Educational Needs during Fourth-Year Emergency Medicine Clerkship. Teaching and Learning in Medicine, 25, 24-30. https://doi.org/10.1080/10401334.2012.741546

Gooding, H. C., Ziniel, S., Touloumtzis, C. et al. (2016). Case-Based Teaching for Interprofessional Postgraduate Trainees in Adolescent Health. Journal of Adolescent Health, 58, 567-572. https://doi.org/10.1016/j.jadohealth.2016.01.011

Ilgen, J. S., Bowen, J. L., McIntyre, L. A. et al. (2013). Comparing Diagnostic Performance and the Utility of Clinical Vignette-Based Assessment under Testing Conditions Designed to Encourage Either Automatic or Analytic Thought. Academic Medicine, 88, 1545-1551. https://doi.org/10.1097/ACM.0b013e3182a31c1e

Li, J. J., Wu, Q. M., Yu, T. et al. (2016). Construction of the Training Mode of the Combination of Clinical Medical Professional Degree Graduate Education and Resident Standardized Training. Creative Education, 7, 802-806. 
Reeves, S., Perrier, L., Goldman, J., et al. (2013). Interprofessional Education: Effects on Professional Practice and Healthcare Outcomes (Update). Cochrane Database of Systematic Reviews, 3, CD002213. https://doi.org/10.1002/14651858.CD002213.pub3

Yeung, M., Beecker, J., Marks, M. et al. (2010). A New Emergency Medicine Clerkship Program: Students' Perceptions of What Works. CJEM, 12, 212-219.

https://doi.org/10.1017/S1481803500012264 